\title{
EFFECT OF PLANT RESIDUES ON AM FUNGI
}

\author{
Geeta Shrestha Vaidya*, K. Shrestha** and H. Wallander*** \\ *Nepal Academy of Science and Technology (NAST), Khumaltar, Lalitpur, Nepal. \\ **Natural History Museum, Swayambhu, Katmandu, Nepal. \\ ***Microbial Ecology Lab, Lund University, Sweden.
}

\begin{abstract}
In this study we have investigated the effect of organic matter on growth of an arbuscular mycorrhizal (AM) fungi in eroded slopes in Nepal such as Forest in Kavre District. Different types of organic matter (leaves of Thitonia diversifolia, Eupatorium adenophorum, Lantana camara, farm compost) and tri-superphosphate were mixed with eroded soil. The mesh bags were buried around trees of eroded site. The mesh bags were harvested after 6 months and the AM fungi in the mesh bags was quantified by analysing the AM spores.
\end{abstract}

Key words: Organic matters; Arbuscular mycorrhizal fungi; Fertilizers and forest.

\section{INTRODUCTION}

Organic farming is the best choice that can help agriculture and environment. The fertility of soil is also influenced by the incorrect use of fertilizers and harmful effects of pesticides. Excessive use of chemical fertilizers (ammonium sulphate) causes acidity in the soil. The quantity of chemical fertilizer used per hectare in Nepal is very low as compared to other countries, but farmers regularly use chemical fertilizer in Kathmandu valley and some of the districts in Terai have started to experience its adverse effects on soil quality.

Soils of Nepal are deficient in N,P,K due to shortage of organic matter in the soils (Shrestha Vaidya et al. 2008). Therefore incorporation of organic matter is necessary for improvement and fertility of soil. Organic matter can replace the use of chemical fertilizers as much as possible

In the early 1990s, however, fertilizer became a target of criticism mainly because of heavy use in developed countries, where it was suspected of having an adverse impact on the environment through nitrate leaching, eutrophication, greenhouse gas emissions and heavy metal uptakes by plants. Plant nutrition in future will require the judicious and integrated management of all sources of nutrients in agricultural fields and forest fields. Prevention of soil erosion is equally important for maintenanace of soil fertility and environment protection. So, there is an urgent need to control erosion prevent potential sediment disaster in Nepal (Shrestha Vaidya et.al 2002). Therefore mycorrhizal fungi are essential for the establishment of tree seedlings and for their good growth (Shrestha Vaidya et al. 2002, 2005).

So, addition of organic matter can have a beneficial effect on the growth of indigenous AM fungi in nutrient limited soil (Caravaca et al. 2002; Gaur \& Adholeya 2002). Organic amendments enhance spore production (Johnson \& Mc Graw 1988,
Douds et al. 1997, Shrestha Vaidya et al 2008). Organic matter addition to the soil in eroded sites could thus be an appropriate to enhance the beneficial effect of AM fungi on soil stabilization and plant establishment and it also protects environment over the long term and reducing cost of production.

\section{MATERIALS AND METHODS}

The eroded soil was collected from a degraded site at Bisankhunarayan. Forty-five g of eroded soil was put in nylon mesh bags and was mixed with different types of organic matter or left unmixed as control.We used 5 gms of dried leaves and dried compost (10\% by weight) as organic matter. Fully expanded leaves of three easy available plant species (Tithonia diversifolia, Lantana camara and Eupatorium adenophorum) were collected from border rows in farmer's fields and near roadsides and the compost was collected from a local farmer . We also included one treatment of rock phosphate. In this case $45 \mathrm{mg}$ Tri-superphosphate were mixed with $50 \mathrm{~g}$ of eroded soil. This represents approximately 40 - $50 \mathrm{~kg}$ $\mathrm{P}$ per hectare which is an amount usually used by local farmers. The mesh bags that were used as controls were filled with $50 \mathrm{~g}$. of eroded soil without any amendments. In total 6 treatments were included (control, Tithonia diversifolia, Lantana camera, Eupatorium adenophorum, compost and rock phosphate). The mesh bags were buried to a depth of about $10 \mathrm{~cm}$ where plant roots had the highest density ( Shrestha Vaidya et al., 2008).

\section{Spore Analysis:}

The AM fungal spores within $25 \mathrm{~g}$ of the soil and amendment mixtures inside the mesh bags were extracted, identified and quantified. Spores were extracted using wet sieving and sucrose density gradient centrifugation (McKinney and Lindsey 1987). Spores were mounted in polyvinyl alcohol on slides and examined using a compound microscope. Species were

Author for Correspondence: Geeta Shrestha Vaidya, Nepal Academy of Science and Technology (NAST), Khumaltar, Lalitpur, Nepal. E-mail:geetashrestha1@hotmail.com 


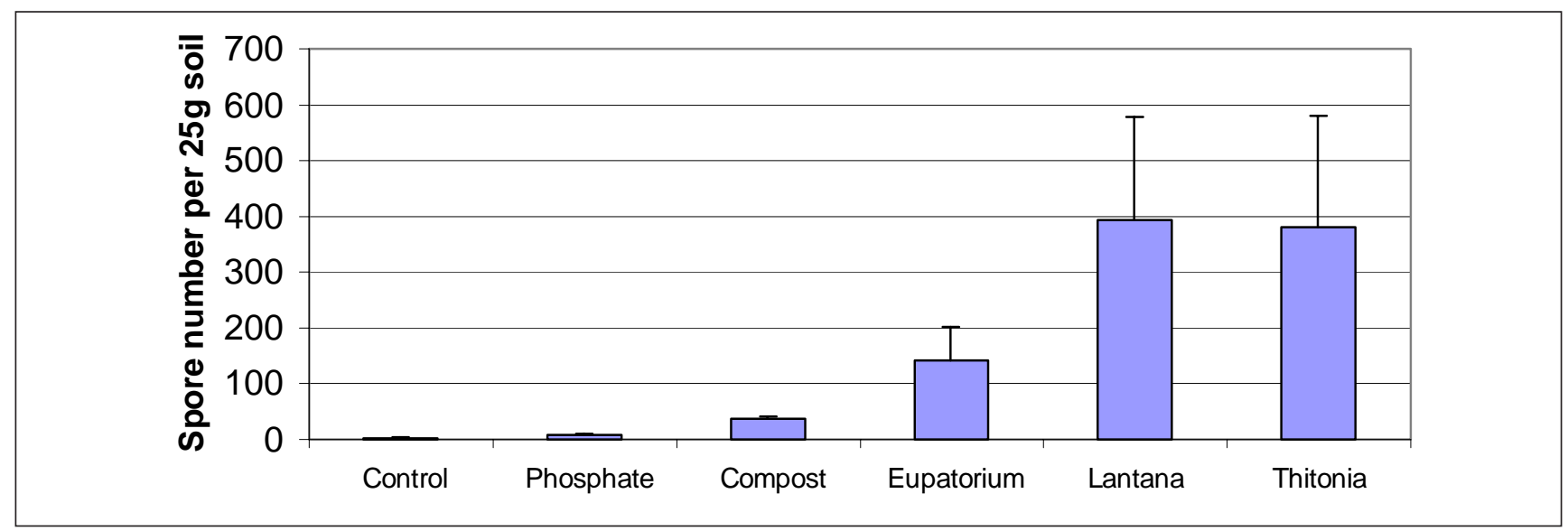

Figure 1: Analysis of Endomycorrhizal spores (AM spores) in each mesh bag having different organic matter.

identified to species using taxonomic characteristics described in INVAM (2005) and Schenck and Perez (1990).

Weighed 25 g. of soil samples, and mixed in a substantial volume of water and decanted through a series of sieves $(750 \mu$, $250 \mu, 100 \mu$ and $50 \mu$ ) after allowing heavy soil particles to settle for a few seconds. This washing and decanting process was repeated until the water became clear. Roots and coarse debris were collected on a coarse. Then these finely kaolin clay remaining last sieve (50 $\mu$ ) transfer to centrifuge tube then water was added in equal weight in each four tube and then centrifuged it for 3 minutes at 2000 RPM. After this supernatant and floating debris was discarded.

The next step involved re-suspending the pellet in 50\% sucrose by vigorously shaking tightly stopper tubes. The samples were then centrifuged for 1 minute at 2000 RPM to separate spores from denser soil components. Immediately after centrifugation, spores in the sucrose supernatant were poured onto the finest sieve $(50 \mu)$ and carefully were washed with water to remove the sucrose.

After rinsing the spores, were washed onto a pre-wetted filter paper in a Buchner funnel before vacuum filtration. In this we used whatman filter paper for spore counting. Semi- permanent microscope slide preparations of spores were made using polyvinyl alcohol-lacto-glycerol (PVLG) . Spores on microscope slides were squashed to reveal inner -wall layers and then were used dissecting microscope for identification ( Brundrett et al 1996 and Schenck and vonne Perez 1990).

\section{RESULTS AND DISCUSSION}

Eroded soil had extremely low levels of, N, P, K, pH and organic matter ( Shrestha Vaidya et al 2008). Addition of all types of organic matter had a strong positive influence on AM biomass (Fig. 1). Addition of organic matter had a positive influence on formation of AM spores. The mesh bags with compost, rock phosphate, or eroded soil contained significantly lower spore numbers compared to the three treatments with dried leaves. So in this study Lantana has shown better effect than Thitonia and Eupatorium. Thitonia has also shown good effect than Eupatorium but compost is better than tri-superphosphate.
The mesh bags had the following amendments: control (no amendment), rock phosphate, dried leaves of Tithonia diversifolia, Lantana camara, Eupatorium adenophora and farmers compost).

The higher yields for the first crop with applications of the higher quality Tithonia are due to a combination of more $\mathrm{P}$ and $\mathrm{N}$ added and faster release patterns of $\mathrm{P}$ and $\mathrm{N}$ from $\mathrm{Ti}-$ thonia as compared to senna.In this result addition of Tithonia diversifolia was found better than the trisupephospate, same result was shown by Jama et.al. (2000). Increased hyphal growth in the soil with increased organic C content was consistent for the two AM fungi (Joner and Jackboson, 1995).

We have seen that growth of AM in degraded soil is highly stimulated by the presence of organic matter. Different types of organic matter had similar positive influence on AM growth. Addition of rock phosphate on the other hand had no effect on AM growth. Number of AM spores was also positively influenced by organic matter addition. Added leaves of Lantana camara and Tithonia diversifolia had a stronger positive influence on AM spore formation than other organic materials.

The beneficial role of organic matter may also be related to an improvement of physical properties like increased soil porosity and reduced mechanical resistance to hyphal growth through the soil (Joner et al., 1995). Giovanetti and Avio (1985) found that additions of different materials, which increased the pore volume in soil, had a beneficial effect on mycorrhizal growth response, colonization and spore numbers.

Our result has shown that Lantana and Tithonia are better than other treatments. Same type of report was reported by Nziguheba et al.(2000). He was reported that the effect of organic materials on resin $\mathrm{P}$ was dependent on the quality of the residue. Tithonia and Lantana with a high P content ( $>2.5 \mathrm{~g}$ $\mathrm{kg}^{-1}$ ) resulted in high resin $\mathrm{P}$ values.

Improved nutrient and water uptake by the planted tree can expected in response to better AM growth and the positive effect on the growth of AM is in good agreement with results obtained by other authors, who also found that organic matter increased AM fungal hyphae growth (Labidi et al., 200x, Nicolson, 1959; Koske et al., 1975; Joner and Jakobsen, 1995) 
and AM spore formation (Douds et al. 1997; Baby and Manibhushanrao 1996; Muthukumar and Udaiyan, 2000; Jeffries and Barea 2001). In addition, St.John et al. (1983), Frey and Ellis (1997) and Friberg (2001) found that AM fungal hyphae grew best in soils with a high amount of organic matter which was shown in results.

Organic agriculture (OA) causes much less environmental pollution, particularly of ground water supplies. Moreover, nitrate leaching rates per hectare in OA systems are roughly half of those in conventional agriculture systems ( Stolze et al., 2000 in FAO, 2002).

OA techniques improve soil structure and increase soil organic matter, thereby improving the soil's water retention capacity. It has the additional social benefit of augmenting supplies of drinking water (FAO, 2002). The improved soil structure also reduces soil erosion, which is a leading cause of soil degradation worldwide with a negative impact on agricultural yields (FAO 2002). A long term trial study in switzerland revealed 50 to 80 per cent more earthworms on organically managed farms as compared to conventionally managed ones (Pfiffiner and Mader, 1997 in FAO, 2002). A separate study found that organic soils in Switzerland had up to 90 per cent higher total mass of micro-organisms than conventionally managed soils (Fliessbah et al., 2001).

\section{CONCLUSIONS}

The present study provides the first evidence that addition of organic matter amendments may stimulate extraradical growth of AM. It also help for soil quality due to increasing rate endomycorrhiza (AM spores). The application of organic materials reduces the soil bulk density and hence increases total porosity, which has a positive effect on plant growth.

\section{ACKNOWLEDGEMENTS}

We sincerely thank Dr.B.R.Khadge, Chief of Plant Pathology Division (NARC) for his valuable suggestion. The authors would like to thank Dr.D.P.Serchan, Chief of Soil Division (NARC) for providing Tithonia diversifolia plant and also thank to farmers and the field staff for their constant support.

\section{REFERENCES}

Baby, U. I. and Manibhushanrao, K. 1996. Influence of organic amendments on arbuscular mycorrhizal fungi in relation to rice sheath blight disease. Mycorrhiza. 6:201-206.

Brundrett, M.; Bougher, N; Dell, B; Grove, T. and Maljczuk, N. 1996. Working with mycorrhizas in forestry and agriculture. ACIAR Monograph 32: 155-157.

Caravaca, F. J. M. Barea and Roldán, A. 2002. Synergistic influence of an arbuscular mycorrhizal fungus and organic amendment on Pistacia lentiscus L. seedlings afforested in a degraded semi-arid soil. Soil Biology and Biochemistry 34:1139-1145.

Douds, D. D.; Galvez, L.; Franke-Snyder, M.; Reider, G. and Drinkwater, L. E. 1997. Effect of compost addition and crop rotation point upon VAM fungi. Agriculture, Ecosystems ands Environment. 65:257-266.
FAO. 2002. Organic Agriculture, Environment and Food Security. Scialabba N and Hattam C, (Publ) in Rome.

Fliessbach, A., Dalpe, Y and Charest, C 2001. DOK long-term farming systems tial-: microbial biomass, activity and diversity affect the decomposition of plant residues. in R. Rees et al., editors. Sustainable Management of Organic matter: 363 to 369. CABI, London

Frey, J. E. and Ellis, J. R. 1997. Relationship of soil properties and soil amendments to response of Glomus intraradices and soybeans. Canadian Journal of Botany 75:483-491.

Friberg, S. 2001. Distribution and diversity of arbuscular mycorrhizal fungi in traditional agriculture on the Niger inland delta, Mali, West Africa. CBM:s Skriftserie. 3:53-80.

Gaur, A. and Adholeya, A. 2002. Arbuscular- Mycorrhizal inoculation of five tropical fodder crops and inoculum production in marginal soil amended with organic matter. Biology and Fertility of Soils 35:214-218.

Giovanetti, M and Avio, L. 1985. VAM infection and reproduction as influenced by different organic and inorganic substances. In proceedings of the 6th NorthAmerican Conference on Mycorrhizae (R.Molina. Ed.) Forest Research Laboratory. Bend, Oregon

INVAM. 2005. Intenational Culture Collection of Arbuscular and VA Mycorrhizal Fungi http://invam.caf.wvu.edu/.

Jama B, Palm CA and Buresh RJ (1999). Using tithonia and fertilizers on maize in western Kenya. Maseno Agroforestry Research Centre Newsletter, ICRAF. Nairobi, Kenya. 6: 3-4.

Jeffries, P. and Barea, J.M.; 2001. Arbuscular Mycorrhiza- a key component of Sustainable Plant Soil Ecosystems. In: The Mycota A Comprehensive Treatise on Fungi as Experimental Systems for basic and Applied Research. Springer-Verlag Berlin Heidelberg. 95-108.

Johnson, N. C., and McGraw A. C. 1988. Vesicular-arbuscular mycorrhizae in taconite tailings II. Effects of reclamation practices. Agriculture Ecosystems and Environment 21:143-152.

Joner, E. J., and Jakobsen, I. 1995. Growth and extra cellular Phosphatase activity of arbuscular mycorrhizal hyphae as influenced by soil organic matter. Soil Biology and Biochemistry 27:1153-1159.

Koske, R.E.; Sutton, J.C. and Sheppard, B.R. 1975. Ecology of endogone in Lake Huron sand dunes. Canadian Journal of Botany. 53:87-93.

Labidi, S.; Nasr, H.; Zouagui, M. and Wallander, H. 200x. Effects of compost addition on extra-radical growth of arbuscular mycor-

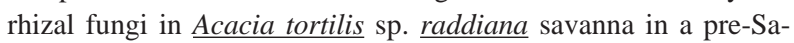
haran area. Applied Soil Ecology (accepted).

McKenney, M. C. and Lindsey, D. L. 1987. Improved method for quantifying endomycorrhizal fungi spores from soil. Mycologia 79:779-782.

Nicolson, T. H. 1959. Mycorrhizae in the gramineae. I. Vesiculararbuscular endophytes, with special reference to the external phase. Transactions of the British Mycological Society 42:421-438.

Nziguheba, G.; Merckx, R.; Palm, C. A. and Rao, M. R. 2000. Organic residues affect phosphorus availability and maize yields in a Nitisol of Western Kenya. Biology and Fertility of Soils 32:328-339.

Pfiffiner, L. and Mader, P. 1997. Effects of biodynamic, organic and conventional production systems on earthworm populations. Entomological research in organic agriculture. Biological Agriculture and Horticulture, 15:3-10. 
Paradis, R.; Dalpe, Y. and Charest, C. 1995. The combined effect of arbuscular mycorrhizas and short term cold exposure on wheat. New Phytol. 129: 637-642.

Schenck, N. C. and Perez, Y. 1990. Manual for the identification of VA mycorrhizal fungi. Synergistic Publications, Gainesville, Florida, USA.

Shrestha, G. 1999 b. The role of ectomycorrhiza in the forestry development in Nepal. In: BIO-REFOR . Proc of Nepal Workshop (28 Nov.-2 Dec, 1999), Kathmandu, Nepal. pp: 178-182

Shrestha Vaidya, Geeta and Piya Sujan. 2002. Study of Antagonistic Action of Two ectomycorrhizal fungi isolated from Pine forest of Dadeldhura. Proc. International Seminar on Mountain, March 6-8: 571-577.

Shrestha Vaidya Geeta; Shrestha, K. and Wallander, H. 2005. Antagonistic Study of Ectomycorrhizal Fungi Isolated from Baluwa Forest (Central Nepal) against with pathogenic Fungi and Bacteria. Scientific World Vol. 3, Number 3, July 49 - 52 .

Shrestha Vaidya G,; Shrestha K.; Khadge, B.R.; Johnson, N.C. and Wallander, H. 2008. Organic matter stimulates arbuscular mycorrhizal fungi in Bauhinia purpurea and Leucaena diversifolia plantations on eroded slopes in Nepal . Restoration Ecology Vol. 16, No. 1, pp. 79-87.
St.Arnaud,M.,Hamel, C.,Vimard, B.,Caron,M.\& Fortin,J.A.(1995). Altered growth of fusarium oxysporum f.sp. chrysanthemi in an in vitro dual culture system with the vesicular arbuscular mycorrhizal fungus Glomus intraradices growing on Daucus carota transformed roots. Mycorrhiza 5, 431-438.

St. John, T. V.; Coleman, D. C. and Reid, C. P. P. 1983. Association of vesicular- arbuscular mycorrhizal hyphae with soil organic particles. Ecology 64:957-959.

Stolze, M. et al. 2000. The environmental impacts of organic farming in Europe. Organic farming in Europe , 6. University of StuttgartHohenheim, Stuttgart.

UNEP 2006. Annual report “Afforestation and Adaptation” United Nations Environment Programme. pp.30.

Wright, S. F. and Upadhyaya, A. 1998. A survey of soils for aggregate stability and glomalin, a glycoprotein produced by hyphae of arbuscular mycorrhizal fungi. Plant and soil 198:97-107. Biochemistry. in press. 